\title{
Spatial Differentiation of China's Low Carbon Development
}

\author{
Jinping Zhang \\ College of Environment and Planning \\ Liaocheng University \\ Liaocheng, China \\ maryzhjp@126.com
}

\author{
Dandan Meng \\ College of Environment and Planning \\ Liaocheng University \\ Liaocheng, China \\ 719103087@qq.com
}

\author{
Jie Dong \\ College of Environment and Planning \\ Liaocheng University \\ Liaocheng, China \\ dongjie@lcu.edu.cn
}

\begin{abstract}
How to achieve regional development with less carbon is the focus of attention of the scientific community. In this paper, with the basic spatial unit of 301 prefecture-level administrative region in China, the relatively refined system of quantitative indicators was established. The 2010 low carbon development (LCD) level is divided into four primary types and eight subtypes based on different combinations of indicators. Study shows that, China's development is primarily high-carbon and relatively high-carbon types, and low-carbon and relatively low-carbon types are distributed below the "Hu line". The global differentiation characteristics of China's LCD are important for policy-making of low carbon development of different types of regions.
\end{abstract}

Keywords- low carbon development; the "Hu Line"; prefecturelevel administrative region; China

\section{INTRODUCTION}

Low carbon development (LCD) has become an important adaptation strategy for countries to address global climate change. However, at the international level, the connotation of LCD has not yet formed a unified opinion (Mulugetta et al., 2010). It is not only very difficult but also unnecessary to strictly regulate the definition of LCD in the international scale, because economic and social programs for countries to consolidate their development priorities are totally different. Recent studies tend to define LCD considering the regional scale and its actual development (Jia et al., 2012; Shrestha et al. 2012), especially for developing countries represented by China (Zhou et al., 2011; Su et al., 2012). As DFID White Paper said, low carbon development means using less carbon for growth, which represents the essential characteristics of LCD. Government, business and academia are all in favor of integrating the effects of climate change into the practice of regional development according to the concepts and principles of LCD, which is considered to be an important measure to achieve poverty reduction, economic growth and better health purposes.
The current measurement model of LCD level is inheritance and deepening of similar mode of regional sustainable development evaluation. Although, to some extent, it can reflect the low-carbon characteristics of regional development, it still follows the complex index system design in general. Serious information overlap and balancing out of indicators make it difficult to effectively guide the practice of regional LCD. This study proposes a relatively refined measurement index system of LCD level based on prefecturelevel administrative region, to explore the types and spatial differentiation characteristics of China's LCD in 2010.

\section{DATA AND METHODOLOGY}

\section{A. Indicators and the Data Processing}

Taking the availability of data into account, choose the 301 prefecture-level administrative regions belonging to the 31 provinces (autonomous regions and municipalities directly under the Central Government) in mainland China as the basic space unit of research. According to the recommendations of experts, China's LCD level should be measured by comprehensive analysis of indicators from low-carbon economy, low-carbon society and low-carbon environment due to the limitation of prefecture-level research scale. In order to ensure independence, first of all, calculate Pearson correlation coefficients for indicators of each criterion layer, and then eliminate indicators that are significantly correlated with most variables $(\alpha=0.05)$ and 12 indicators remain to build the index system (Table 1). Apply range transform method to normalize the positive and negative acting indicators and make them all between 0 and 1 . In this paper, the per capita indicators are derived from dividing the corresponding aggregate indicators by the total population at the end of the year, in order to avoid differences due to various statistical standards.

Regional energy consumption data come from the provincial 2010 and 2011 statistical yearbook. The economic, social and environmental data, such as GDP, the total 
population, come mainly from the "China City Statistical Yearbook" and provincial statistical yearbook from 2006 to 2011; moreover, the GDP data are converted into comparable prices of 2005. For regions lack of energy consumption data, firstly, according to the provincial Energy Balance Sheet of the study year, the total energy consumption is broken down into four parts of energy consumption of life, the primary industry, secondary industry and tertiary industry. Then, based on the population and total output value of the three major industries respectively, four parts of the energy consumption of the prefectural-level regions are estimated, which are further added up to the total energy consumption of the prefectural-level regions. Forest coverage, as well as other missing data has been mostly taken from the regional National Economic and Social Development Statistics Bulletin, Report on the Work of the Government, and information publish on the web bye the statistical departments.

TABLE I. MEASUREMENT INDEX SYSTEM OF LOW CARBON DEVELOPMENT LEVEL

\begin{tabular}{|c|c|c|c|}
\hline $\begin{array}{l}\text { Goal } \\
\text { layer }\end{array}$ & $\begin{array}{l}\text { Criterion } \\
\text { layer }\end{array}$ & Index layer & $\begin{array}{l}\text { Acting } \\
\text { direction } \\
\text { of } \\
\text { indicator }\end{array}$ \\
\hline \multirow{12}{*}{$\begin{array}{l}\text { Measure- } \\
\text { ment of } \\
\text { LCD } \\
\text { level }\end{array}$} & \multirow{5}{*}{$\begin{array}{l}\text { Low-carbon } \\
\text { economy }\end{array}$} & $\begin{array}{l}\text { Energy consumption per unit } \\
\text { of GDP (ton of SCE per ten } \\
\text { thousand yuan) }\end{array}$ & - \\
\hline & & $\begin{array}{l}\text { Elasticity coefficient of energy } \\
\text { growth (GDP growth rate / } \\
\text { growth rate of energy } \\
\text { consumption) }\end{array}$ & - \\
\hline & & $\begin{array}{l}\text { GDP per capita（ten thousand } \\
\text { yuan })\end{array}$ & + \\
\hline & & $\begin{array}{c}\text { The proportion of tertiary } \\
\text { industry }(\%)\end{array}$ & + \\
\hline & & $\begin{array}{l}\text { The proportion of } \mathrm{R} \& \mathrm{D} \\
\text { expenditure }(\%)\end{array}$ & + \\
\hline & \multirow{4}{*}{$\begin{array}{l}\text { Low-carbon } \\
\text { society }\end{array}$} & $\begin{array}{c}\text { Per capita electricity } \\
\text { consumption (KW.h per } \\
\text { person per year) }\end{array}$ & - \\
\hline & & $\begin{array}{l}\text { Urban construction land per } \\
\text { capita (square kilometers per } \\
\text { ten thousand people) }\end{array}$ & - \\
\hline & & $\begin{array}{l}\text { Public transport vehicle } \\
\text { ownership per ten thousand } \\
\text { people }\end{array}$ & + \\
\hline & & $\begin{array}{c}\text { Per capita } \mathrm{CO}_{2} \text { emissions from } \\
\text { urban gas (kilogram per } \\
\text { person) }\end{array}$ & - \\
\hline & \multirow{3}{*}{$\begin{array}{l}\text { Low-carbon } \\
\text { environment }\end{array}$} & Forest coverage $(\%)$ & + \\
\hline & & Urban greenbelt cover $(\%)$ & + \\
\hline & & $\begin{array}{l}\mathrm{SO}_{2} \text { emissions per unit of gross } \\
\text { industrial production (ton per } \\
\text { one hundred million yuan) }\end{array}$ & - \\
\hline
\end{tabular}

\section{B. Integration of Indicators}

In each criterion layer, integrate the normalized indicators in accordance with the equal-weighted linear weighting method, and calculate composite index of low-carbon economy, lowcarbon society and low-carbon environment. The composite index with higher scores indicates a more low-carbon development of the subsystem, while the contrary means a high-carbon development. Each composite index is divided into high $(\mathrm{H})$ and low $(\mathrm{L})$ class using the natural breaks method, and then a total of eight subtypes of LCD have formed from "HHH" to "LLL" according to the level of a combination of the three indices. For a prefecture-level administrative region, if the three indices are all " $\mathrm{H}$ ", the development is the low-carbon type; else if they are all "L", it is the high-carbon type. At the same time, if there are two " $\mathrm{H}$ " and one " $\mathrm{L}$ " in the three indices, it is the weaker low-carbon type; and if there are two "L" and one " $\mathrm{H}$ ", it is the weaker high-carbon type. In this way, eight subtypes of LCD have been combined into four primary types of LCD.

\section{RESULTS AND ANALYSIS}

\section{A. Spatial Distribution Characteristics of the Primary Types of $L C D$}

In general, the China's LCD level based on the 301 prefecture-level administrative regions in 2010 gradually transit from the high-carbon type of the Northwest to the low-carbon type of the southeast (Figure 1). The shift line of "HegangPu'er line" that can distinguish the high-carbon and weaker high-carbon area from the low-carbon and weaker low-carbon area is parallel to the famous "Hu line" (i.e. the population dividing line of "Heihe-Tengchong" line), which can be defined as the dividing line of China's LCD. The "Hu line" reveals a high degree of correlation between climate and population density (Wu et al., 2008). This study happens to hold the same view. The reason is that, as one of the key factors that affect climate change, energy consumption and its synthetic action in the economic, social and environmental subsystems are the important considerations when design the regional LCD index system. China's LCD dividing line has the same trend with the "Hu line", which is the spatial expression and powerful evidence of the viewpoint of "distribution of factors that determine industrial layout and regional development, such as urban and traffic conditions, labor, technology and capital, are closely related with the "Hu line". However, the lack of analysis of the western region, coupled with the combined effects of multiple indicators, make the position of LCD line a certain degree of offset with the "Hu line".

\section{B. Spatial Distribution Characteristics of the Subtypes of $L C D$}

Low-carbon $(\mathrm{HHH})$ and weaker low-carbon (HHL, HLH and LHH) type are mainly located in the right side of the LCD line, that is, in southern and eastern China, which are typical LCD areas. In these regions, economic structure is more appropriate with moderate size of the city and its population. Investment in transportation and other public facilities are also reasonable with properly controlled energy structure and consumption. Meanwhile, their natural environment is superior and most low-carbon targets are higher than the mean. Highcarbon (LLL) and weaker high-carbon (HLL, LHL and LLH) type are mainly located in the left side of the LCD line, that is, in northwest China. Most of these regions are important source of energy in the country with sparse population and fragile ecosystems, where economic development relies on the heavy industries consuming a large number of coals. With most lowcarbon targets being lower than the mean, they need to do more 
to increase the investment in research and development of carbon reduction technology, upgrade the industrial structure and gradually optimize the energy structure, and improve the natural environment and urban greening.

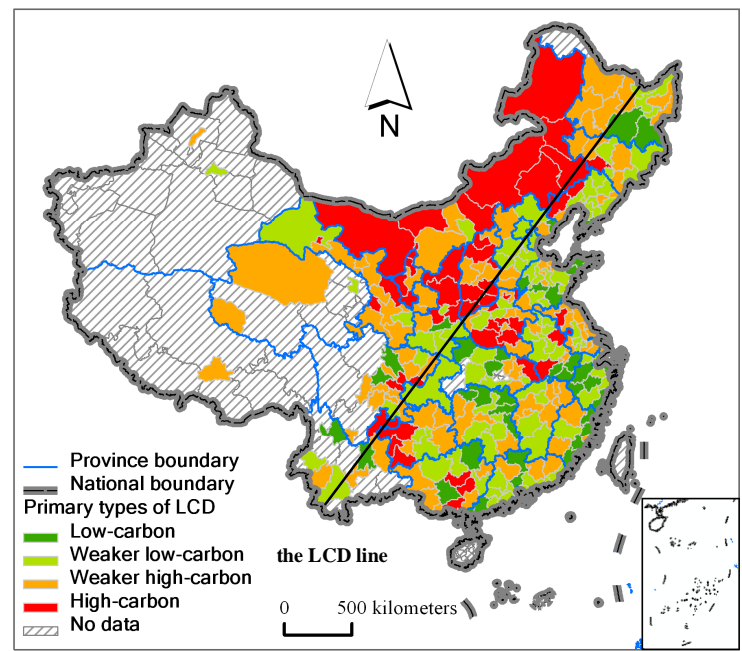

Figure 1. The spatial distribution of China's low carbon development level

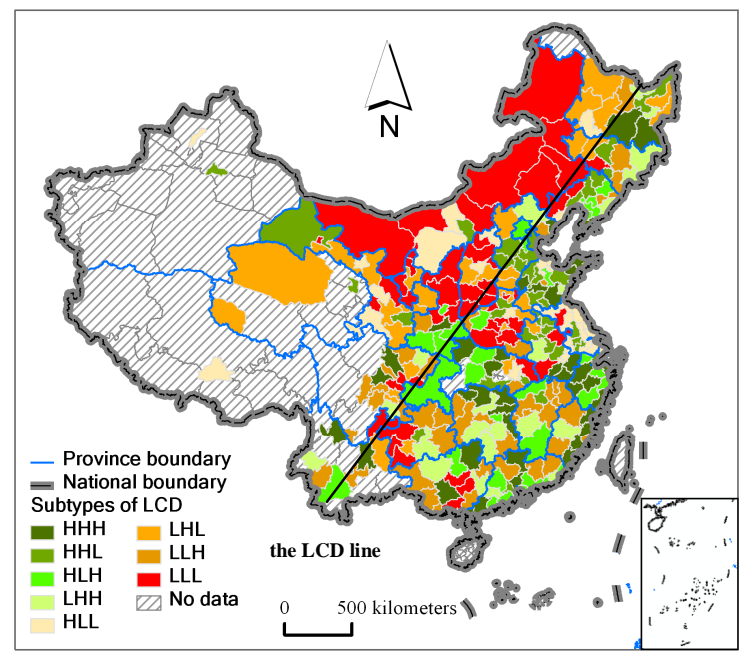

Figure 2. The spatial distribution of China's low carbon development level

\section{CONCLUSIONS AND DISCUSSION}

The spatial analysis of LCD level based on the prefecturelevel administrative regions is of great significance for targeted urban and regional development policy-making of different types of areas. In this paper, China's LCD level of 301 regions in 2010 is quantified, and its spatial differentiation characteristics are studied. We mainly draw the following conclusions:

Indicators and method for measurement of LCD level established in the prefecture-level scale are both refined and consistent with the nature of LCD. The LCD level has been measured from three aspects of development of low-carbon economy, low-carbon society and low-carbon environment. The index system not only reflects concepts of per capita and relative value of low carbon, but also emphasizes the connotations of the total consumption of energy and absolute reduction of carbon emission. The three composite indices of criterion layer haven't been further integrated by the linear weighting method, but according to their different combinations to form several types, which in conducive to the clear discrimination of low-carbon scenario of regional development and the trace analysis of changes of indicators.

In the global space, the LCD level of 301 prefecture-level regions can be divided into four primary types and eight subtypes. High-carbon and weaker high-carbon types are mainly located in the left side of the dividing line of LCD, the most important task of which is to change the high energyconsuming industrial structure and improve the fragile ecology. Low-carbon and weaker low-carbon types are mainly located in the right side of the dividing line of LCD, which need to make trade-offs between LCD of economy, society and environment in the process of rapid industrialization and urbanization, and strive to create the optimal growth mode. The LCD line is parallel to the "Hu line", indicating the spatial dependence and close ties between China's LCD mode and the formation of the "Hu line".

\section{ACKNOWLEDGEMENTS}

This work was supported by the National Basic Research Program of China (No. 2012CB955804), National Natural Science Foundation of China (No. 41171438, 41201602), National Postdoctoral Science Foundation of China (No. 2012M511108), and Natural Science Foundation of Shandong province (ZR2010DL008).

\section{REFERENCES}

[1] J. S. Jia, Y. Fan, and X. D. Guo, "The low carbon development (LCD) levels' evaluation of the world's 47 countries (areas) by combining the FAHP with the TOPSIS method," Expert Systems with Applications. Oxford, vol. 39, pp. 6628-6640, June 2012.

[2] Y. Mulugetta, and F. Urban. "Deliberating on low carbon development," Energy Policy. Oxford, vol. 38, pp. 7546-7549, December 2010.

[3] R. M. Shrestha, and S. R. Shakya, "Benefits of low carbon development in a developing country: case of Nepal," Energy Economics. Oxford, vol. 34, pp. S503-S512, December 2012.

[4] M. R. Su, C. Liang, B. Chen, S. Q. Chen, and Z. F. Yang, "Low-carbon development patterns: observations of typical Chinese cities," Energies. Basel, 5, pp. 291-304, February 2012.

[5] J. Wu, and Z. Wang, "Agent-based simulation on the evolution of population geography of China during the past 2000 years," Acta Geographica Sinica. Beijing, vol. 63, pp. 185-194, November 2008. (in Chinese)

[6] N. Zhou, S. Ohshita, L. Price, and S. Ohshita, "A Low carbon development guide for local government actions in China," Carbon Management. London, vol. 2, pp. 455-469, August 2012. 